\title{
A puzzle about accommodation and truth
}

\author{
Derek Ball $^{1}$ (1) Torfinn Thomesen Huvenes ${ }^{2}$ (1)
}

Accepted: 25 June 2021 / Published online: 4 July 2021

(C) The Author(s) 2021

\begin{abstract}
The purpose of this paper is to present and discuss a puzzle involving accommodation. The puzzle is based on three assumptions. The first assumption is that accommodation takes place after an utterance. The second assumption is that accommodation can make a difference to the truth-value of an utterance even if the utterance is not about the future. The third assumption is that something that takes place after an utterance cannot make a difference to the truth-value of the utterance unless the utterance is about the future. Since these assumptions are jointly inconsistent, one of them must be false. The question is which one we ought to reject. The majority of the discussion is devoted to discussing each of the options, and the tentative conclusion is that the most plausible strategy is to reject the third thesis. That amounts to saying that something that takes place after an utterance can make a difference to the truth-value of the utterance even if the utterance is not about the future.
\end{abstract}

Keywords Accommodation · Conversational score · Disagreement · Externalism · Relativism

Torfinn Thomesen Huvenes

torfth@hotmail.com

Derek Ball

db71@st-andrews.ac.uk

1 Department of Philosophy, University of St Andrews, Edgecliffe, The Scores, St Andrews, Fife KY16 9AL, Scotland

2 Department of Historical, Philosophical and Religious Studies, Umeå University, Humanisthuset, 90187 Umeå, Sweden 


\section{Introduction}

It is widely agreed that the truth of an utterance can depend on features of the situation in which the utterance is made. For example, if someone says, "I am hungry", whether that utterance is true depends on who is speaking. Lewis's (1979) account of phenomena of this kind appeals to the notion of a conversational scorea systematisation of all of the features of a conversation that might be relevant to the truth of utterances in that conversation. ${ }^{1}$ When a speaker makes an utterance, the truth of the utterance depends on the components of the conversational score. However, sometimes the truth of the utterance requires something that is missing from the conversational score. In such cases, Lewis proposes that the conversational score can be changed by a process of accommodation. Unless someone objects, the required components are added to the conversational score and the conversation can proceed as if the components were already in place.

This notion of accommodation has been influential among linguists and philosophers of language. While accommodation has received considerable attention, we want to draw attention to a puzzle involving accommodation that has not received the same level of attention. ${ }^{2}$ The puzzle starts from the assumption that nothing that happens after an utterance can make a difference to the truth-value of the utterance unless the utterance is about the future. However, this conflicts with two plausible assumptions about accommodation. First, accommodation takes place after an utterance. Second, accommodation can make a difference to the truth-value of the utterance even if it is not about the future. Something has to give. The purpose of the following discussion is to evaluate different ways of solving this puzzle. In order to do that, we will go through each of the assumptions and assess their plausibility.

Before we proceed, it is worth emphasizing that we are working with a broad notion of accommodation. Much of the literature on accommodation in philosophy of language and linguistics focuses on presupposition accommodation. ${ }^{3}$ For instance, Stalnaker (1998, p. 284) argues that an utterance of "I have to pick up my cat" is appropriate only if it is presupposed in the conversation that the speaker owns a cat. If this is not presupposed prior to the utterance, the presupposition can be brought into place by means of accommodation. However, following Lewis (1979), we take accommodation to be a broader phenomenon. What is accommodated may be a presupposition, but it may be something else. One of Lewis's (1979, p. 352) examples is that if someone says, "France is hexagonal", the truth-value of

\footnotetext{
1 Following Lewis (1979), we are going to use the term "conversational score", as opposed to the more familiar term "context". For the purpose of the following discussion, we suspect that it would not do much harm to replace "conversational score" with "context". However, there are some ways of thinking about context that would make the discussion to follow more complex. For example, Lewis's (1980) conception of context as a centered world, and Stalnaker's (1998) conception of context as a set of worlds, would fit badly with the way we talk about accommodation. Our discussion could be adapted to these notions of context, but in order to keep things simple, we will set them aside.

2 Notable exceptions include Richard (1995) and Ball (2018). We revisit their respective views in Sect. 5, below.

3 See e.g. Lewis (1979, pp. 339-340). See e.g. also Roberts (1989) and Heim (1992).
} 
their utterance is determined by a set of standards, and if an appropriate set of standards is not in place prior to the utterance, it may be accommodated. In fact, for the purpose of the following discussion, cases like "France is hexagonal" are going to be more relevant than cases like "I have to pick up my cat". The main reason for that is that we are interested in cases in which accommodation seems to make a difference to the truth-value of the utterance. In examples like Stalnaker's, it is only the appropriateness of the utterance that seems to be at issue. Insofar as other cases of presupposition accommodation share this feature, they are not going to play a central role in the following discussion. ${ }^{4}$

In Sect. 2 we introduce the puzzle and discuss the relevant notion of accommodation in more detail. The puzzle is generated by three assumptions, and we take it that resolving the puzzle requires giving up one of these assumptions. Sections 3, 4, and 5 discuss each possible resolution of the puzzle in turn. In Sect. 5, we argue that the most promising strategies for resolving the puzzle involve giving up the assumption that nothing that happens after an utterance can make a difference to the truth-value of the utterance unless the utterance is about the future and discuss two ways of developing this strategy. The first is a form of relativism and the second is a form of temporal externalism. Either view can resolve the puzzle. We therefore conclude that there is an important theoretical choice in the foundations of semantics between relativist and externalist views. That is surprising since both views have been considered controversial. Since the considerations that could push us one way or another go well beyond issues of accommodation, this paper does not aim to resolve the question of which view is to be preferred.

\section{The puzzle}

The puzzle itself is fairly straightforward. It relies on the following three assumptions:

1. Accommodation takes place after an utterance.

2. Accommodation can make a difference to the truth-value of an utterance even if the utterance is not about the future.

3. Something that takes place after an utterance cannot make a difference to the truth-value of the utterance unless the utterance is about the future.

From [Thesis 1] and [Thesis 2] it follows that something that happens after an utterance can make a difference to the truth-value of an utterance even if the utterance is not about the future. This is inconsistent with [Thesis 3]. The conclusion is that one of the assumptions must be false.

In order to properly assess the assumptions, we need to say more about accommodation. For the purpose of the following discussion, we will be following Lewis (1979) who presents the notion of accommodation alongside the notion of a

\footnotetext{
${ }^{4}$ By focusing on other cases of accommodation, we also get to sidestep some of the controversial issues surrounding presupposition accommodation. See e.g. Gauker (2008) and von Fintel (2008) for relevant discussion.
} 
conversational score. The components of the conversational score include the various presuppositions and standards that are required when evaluating utterances for truth and acceptability. For instance, Lewis (1979, p. 352) proposes that if someone says, "France is hexagonal", the truth-value of the utterance depends on the relevant standards of precision. ${ }^{5}$

The conversational score evolves throughout a conversation. One way in which the conversational score can be changed is through accommodation. Accommodation may occur when the conversational score does not conform to the requirements of an utterance. For instance, in order for an utterance of "France is hexagonal" to be true, the standards of precision have to be fairly low. If there are no standards of precision or the standards of precision are too high, the components of the conversational score are not what they need to be in order for the utterance to be true. In such cases, the conversational score may be changed in order to make it conform to the requirements of the utterance. For instance, it might be that new standards of precision are added to the conversational score or existing standards are lowered. This is what is known as accommodation.

Whether or not accommodation takes place depends at least in part on how the hearers react. In some cases, like [Case A], the hearers explicitly accept the utterance and thereby signal that they are willing to accommodate.

[Case A]

Mary: France is hexagonal.

John: Yes, and Italy is boot-shaped.

In other cases, accommodation happens without explicit assent. The hearers tacitly accept the changes to the conversational score.

That said, accommodation does not always happen. Hearers can also reject the original utterance. In cases like this, it is the subsequent development of the conversation that determines whether accommodation takes place. On the one hand, if the speaker accepts the hearer's correction, accommodation does not take place. This is what happens in [Case B].

[Case B]

Mary: France is hexagonal.

John: No, you're wrong. Its borders are all crooked. Just look at how Brittany sticks out.

Mary: Okay, I see your point. I was wrong, France isn't hexagonal.

\footnotetext{
5 We are following Lewis in using standards of precision as an example. However, we are not convinced that there is any good evidence that the conversational score contains a parameter for standards of precision. A more linguistically plausible proposal might follow Kennedy (1997) and Kennedy and McNally (2005) in proposing that gradable adjectives such as "hexagonal" map objects to degrees on a scale. In this case, perhaps, the scale represents the extent to which objects approach a geometric hexagon. On this kind of view, the conversational score might need to contain a degree of hexagonality instead of a standard of precision. The semantic details will make no substantive difference to the discussion.
} 
On the other hand, if the speaker continues to defend her original utterance and the hearer eventually concedes, accommodation can still take place. This is what happens in [Case $\mathrm{C}$ ].

[Case C]

Mary: France is hexagonal.

John: No, you're wrong. Its borders are all crooked. Just look at how Brittany sticks out.

Mary: Of course France isn't a perfect geometric hexagon. But it is roughly hexagonal; just look at the map. So I was right.

John: [squints at map] Okay, I see your point. You were right. France is hexagonal after all.

In some cases, it might be that the purpose of the conversation makes a certain reaction more appropriate than another. For instance, it might be more difficult to accommodate an utterance of "France is hexagonal" if the discussion is about teaching geometry to college students than if the discussion is about teaching geography to children. However, in many cases, it appears that the hearers have a choice. They can go along with accommodation, but they can also refuse to do so. Furthermore, there does not appear to be anything about the situation prior to the utterance that makes one reaction appropriate and the other inappropriate. In some cases, the conversation might not have a clear purpose that could determine the appropriate reaction. In other cases, the purpose of the conversation might be compatible with different reactions that are equally appropriate. For instance, if the discussion is about teaching geography to children, Richard (1995, p. 564) observes that the conversation could develop in different ways, with the conversational participants either accepting or rejecting an utterance of "France is hexagonal" depending on the subsequent course of the conversation. This element of choice is a feature of many cases of accommodation that will play an important role in the subsequent discussion.

\section{Rejecting the first thesis}

The first way out of the puzzle is to reject [Thesis 1]. [Thesis 1] says:

1. Accommodation takes place after an utterance.

There are broadly speaking two ways of rejecting this thesis. The first is to accept that accommodation takes place, but deny that it takes place after an utterance. The second is to deny that accommodation takes place at all.

We think that the second option is unattractive. There is room for disagreement about exactly how accommodation works, but it seems hard to deny that there is some genuine phenomenon here. We therefore set this second option aside and focus on the idea that accommodation takes place, but does not take place after an utterance.

If one wants to accept that accommodation takes place, but deny that it takes place after an utterance, there seem to be two possibilities. Accommodation must 
take place either before the utterance, or during the utterance. But accommodation cannot take place before the utterance. Accommodation only takes place when the conversational score does not conform to the requirements of the utterance. If the conversational score had been changed before the utterance, there would not be any need for accommodation. In that case, we would be dealing with a different phenomenon altogether.

This leaves someone who wants to deny [Thesis 1] with one only option, which is to say that accommodation takes place during the utterance. However, this also seems questionable as a response to the puzzle. Simplifying somewhat, whether accommodation takes place depends on whether the hearer accepts or rejects the utterance. When the acceptance or rejection takes place after the utterance, as it does in typical cases, accommodation plausibly also takes place after the utterance.

This is not to deny that there might be some cases in which accommodation takes place during the utterance. For instance, the hearers could be nodding along and signaling that they accept the utterance while the speaker is still speaking. But such cases can be treated as exceptions for the purpose of the following discussion. As long as such cases are ignored when evaluating the other theses, there are still sufficient resources to generate a puzzle.

A theorist who denies [Thesis 1] has to resist this line of reasoning. One way to do that is to distinguish between the utterance event and the speech event. For the purpose of the present discussion, the speech event should be understood as the event of someone producing the relevant speech. ${ }^{6}$ Having made this distinction, the idea is that the utterance event can be extended in time beyond the time of the speech event. The speech event only lasts as long as the speaker is speaking, but the utterance event lasts longer. While the reactions of the hearers take place after the speech event, they still take place during the utterance event. Accordingly, it becomes possible to maintain that accommodation takes place during the utterance in general, and not just in a limited range of cases.

If this is correct, it provides a response to the puzzle as originally formulated. However, we doubt that this resolution is satisfactory. An obvious question is whether there is any independent motivation for thinking about utterances in this way. While it is commonly accepted that utterances are extended in time, it is unclear why one would think that they extend beyond the speech event.

Furthermore, even if the proposal can be motivated, it would simply lead to a reformulation of the puzzle. This can be done by revising [Thesis 1] and [Thesis 3], as we have done below.

1. Accommodation takes place after the speech event.

2. Accommodation can make a difference to the truth-value of an utterance even if the utterance is not about the future.

3. Something that takes place after the speech event cannot make a difference to the truth-value of the utterance unless the utterance is about the future.

\footnotetext{
${ }^{6}$ For the purpose of the present discussion, we will focus on spoken language. However, the same issue arises for written language.
} 
From the revised [Thesis 1] and [Thesis 2], it follows that something that takes place after the speech event can make a difference to the truth-value of an utterance even if the utterance is not about the future. This is inconsistent with the revised [Thesis 3]. Something still has to go. Furthermore, it does not appear that the revised versions of the theses are less plausible than the original versions.

The fact that the puzzle can be reformulated in this way suggests that it is going to be difficult to respond to the puzzle merely by drawing a distinction between the utterance event and the speech event. In the reformulated version of the puzzle, [Thesis 1] makes reference to the speech event, as opposed to the utterance event. This makes it difficult to see how the revised version of [Thesis 1] can be challenged given what has been said so far.

The possibility of denying [Thesis 1] raises a number of interesting questions. However, based on the preceding discussion, it is difficult to see how a rejection of [Thesis 1] can provide an adequate response to the puzzle by itself. We are therefore going to rely on the original formulation of the puzzle in what follows. We now turn our attention to [Thesis 2].

\section{Rejecting the second thesis}

[Thesis 2] says:

2. Accommodation can make a difference to the truth-value of an utterance even if the utterance is not about the future.

[Thesis 2] is plausible because it seems to capture the difference between conversations in which accommodation occurs, and those in which accommodation does not occur. For example, in [Case A], Mary's utterance seems true, but in [Case B], Mary's first utterance seems false. (That is also the view of the participants in the conversation. In [Case A], Mary presumably thinks that it is true, and John agrees with her by saying "Yes". In [Case B], John thinks that Mary's first utterance is false, and Mary agrees with him by saying "I was wrong".) However, plausibly, the cases could be developed so that the only relevant difference between them lies in John's response and Mary's subsequent reaction. All of the facts about Mary and her community that might play a role in determining the standard of precision relevant to her utterance of "France is hexagonal" might be the same in both cases. This could for instance include Mary's intentions and dispositions, the ways experts or ordinary speakers typically use words like "hexagonal", and so forth. But in that case, what makes a difference to the truth-value of Mary's utterance must be whether accommodation takes place, as constituted by John's response and Mary's reaction.

We can regiment the argument as follows:

Premise 1: Mary's utterance of "France is hexagonal" is true in [Case A], but false in [Case B].

Premise 2: The only relevant difference between [Case A] and [Case B] is that accommodation takes place in [Case A], but not [Case B]. 
Premise 3: Mary's utterance of "France is hexagonal" is not about the future. Conclusion: Accommodation can make a difference to the truth-value of an utterance even if the utterance is not about the future.

The argument is valid. So the only strategies for resisting the argument are to deny one of the premises. The first option is to deny the first premise. It is not the case that Mary's utterance in [Case A] is true, and her first utterance in [Case B] is false. Both utterances have the same truth-value, assuming other relevant facts about the cases are the same. The second option is to deny the second premise. If the first premise is true, then it cannot be the case that there are no relevant differences between [Case A] and [Case B], other than those that constitute accommodation. There must be some difference in Mary, her community, or the utterance situation, that explains the difference in truth-value. The third option is to deny the third premise. Although it appears to be about the present, Mary's utterance of "France is hexagonal" is in fact about the future. In what follows, we will argue that all three strategies are problematic.

The first option is problematic because the most natural way of making sense of John's reaction in [Case B] is to say that he is claiming that Mary's utterance of "France is hexagonal" is not true. We could have made this explicit by having John say, "No, that's false". This seems equally acceptable, if a bit stilted in ordinary speech. Furthermore, Mary seems to agree. But the most natural way of making sense of John's reaction in [Case A] is to say that by saying "Yes", he is asserting that Mary's utterance of "France is hexagonal" is true. Again, we could have made that explicit by having John say, "Yes, that's true". So this option would involve attributing error to Mary and John in one case or the other.

Can such an error theory be defended? Perhaps the most promising strategy for doing so would deny that John's reaction should be understood as affirming or rejecting the truth of Mary's claim. Let us suppose that Mary's intentions and dispositions somehow determine the standard of precision relevant to her utterance of "hexagonal". Assuming that she is well-informed about the shape of France, this will more or less guarantee that she is speaking truly. So John should not be understood as disputing the truth of her claim. Instead, John should be understood as affirming or rejecting the appropriateness of Mary's standard. He wants to make a metalinguistic claim about how the word "hexagonal" ought to be used. He either wants to affirm that he and Mary ought to be using "hexagonal" with relatively loose standards of precision on which France counts as "hexagonal", or to reject this usage and advocate stricter standards. ${ }^{7}$

This is a promising way of making sense of John's initial reaction. But it is unsuccessful at making sense of many ways in which the dialogue might continue and the way that Mary and John appear to disagree in [Case C]. First, it cannot make sense of the version of the dialogue where John explicitly says "Yes, that's true" or "No, that's false". Second, it cannot make sense of John's way of supporting his claims. When John says, "Its borders are all crooked", that is a claim that bears on France's shape. It does not bear in any obvious way on whether John and Mary

\footnotetext{
7 See Ludlow (2014) and Plunkett and Sundell (2013) for defense of this kind of strategy in related cases.
} 
ought to use "hexagonal" with one standard of precision rather than another. Thus it is strange for John to advance this consideration if his aim is to convince Mary to adopt a certain way of speaking, and it is strange for Mary to acquiesce. This kind of worry is exacerbated once we consider examples like [Case $\mathrm{C}$ ], in which the conversation continues and further arguments are mustered. Once again, it is hard to understand Mary's claim as bearing on how John ought to use "hexagonal". It just does not seem to offer him a reason to speak in any particular way. It is therefore hard to see how the metalinguistic view can make sense of what is going on as John and Mary give arguments for their views. ${ }^{8}$

Moreover, if Mary's concern is to get John to change how he uses the word "hexagonal", there are practical considerations that she could easily bring to bear: for example, she might offer John a bribe to speak in her preferred way. A big enough bribe would be a good reason for John to apply "hexagonal" to France. But bribes do not seem relevant to what is at issue between Mary and John. A bribe could not really settle the issue of whether France is hexagonal. So, what is at issue between Mary and John is not just a matter of how to use the word "hexagonal". Again, the metalinguistic error theory is problematic.

The second option is also problematic. To defend it would require there to be some facts about Mary and the situation-her intentions, dispositions, interests, purposes, history, ordinary or expert usage in her linguistic community, her audience and their interests and purposes, and so on —at the time Mary says "France is hexagonal", that determine how John ought to respond. In particular, the facts need to determine whether he ought to accommodate or to refuse to accommodate. But this proposal simply misconstrues the phenomenon. Plausibly, it is a datum about the case that John may respond to Mary's utterance either way. Nothing about the situation prior to John's utterance makes one response required and the other impermissible. So no view on which a certain response is required in advance does justice to the case.

Finally, the third option is also problematic. It is very natural to think that Mary's utterance of "France is hexagonal" is about the shape of France at the time of her utterance, and not at all about the future; and it is hard to see what motivation could be given for the contrary view.

If further argument is needed, we can begin by noting that Mary's utterance is in the present tense. She says, "France is hexagonal" rather than "France will be hexagonal". Of course, not all utterances in the present tense attribute features that depend solely on how things are at the time of utterance. Some attribute features which a thing may have or lack in virtue of how things are at other times. For example, it is common at political nominating conventions to introduce a candidate as "the next President of the United States". The candidate may have that feature. But if she does, it is in virtue of things that will happen in the future. Therefore, if, prior to the election, someone says, "Joe Biden is the next President of the United States", there is a clear sense in which that utterance is about the future.

\footnotetext{
$\overline{8}$ This line of argument is developed in more detail in Ball (2020a).
} 
However, Mary's utterance of "France is hexagonal" does not seem at all like this. Mary's utterance attributes to France a particular shape. The shape an object has at a time depends solely on how things are at that time. It is plausible that shape is an intrinsic feature, but even if this is not so, it seems hard to see how shape could depend on what goes on at other times. Since Mary's utterance is in present tense and does not attribute a feature which a thing possesses or lacks in virtue of how things are in the future, Mary's utterance is about the present and not about the future.

All of the options for responding to the argument for [Thesis 2] are problematic. We therefore conclude that [Thesis 2] is well-motivated, and that the rejection of [Thesis 2] would bring with it substantial costs. We turn our attention to [Thesis 3].

\section{Rejecting the third thesis}

The final way out of the puzzle is to reject [Thesis 3]. [Thesis 3] says:

3. Something that takes place after an utterance cannot make a difference to the truth-value of the utterance unless the utterance is about the future.

It is unsurprising that something that takes place after an utterance can make a difference to the truth-value of the utterance if the utterance is about the future. For instance, if someone says, "There will be a sea battle tomorrow", it makes a difference to the truth-value of the utterance whether there is a sea battle the next day. However, we have already argued that Mary's utterance of "France is hexagonal" is not about the future, and that is also true of many other cases of accommodation. In cases like that, [Thesis 3] says that something that takes place after the utterance cannot make a difference to its truth-value.

How could [Thesis 3] be rejected? In general, there are two ways in which something can make a difference to the truth-value of an utterance. The first way is by making a difference to the truth-value of the utterance, but not its content. The second way is by making a difference to the content. As a result, there are two ways of rejecting [Thesis 3]. While the first option leads to a form of relativism, the second option leads to a form of temporal externalism. Both views are controversial. For instance, Brown (2000, p. 178) claims that temporal externalism "will strike many as deeply controversial". Likewise, relativism has had no shortage of critics. In what follows, we will assess both options.

\subsection{Making a difference to truth-value but not content}

Let us start with the first option. The idea is that something that happens after the utterance makes a difference to the truth-value of the utterance without making a difference to its content. This may seem strange given that the utterance is not about

\footnotetext{
${ }^{9}$ See e.g. Stanley (2005, ch. 7), Glanzberg (2007), Stojanovic (2007), and Cappelen and Hawthorne (2009) for criticism of relativism.
} 
the future. However, one can make sense of this by making use of relativist machinery. This is effectively the line that Richard (2008) takes. According to Richard, there is a connection between accommodation and relative truth. This is brought out by his remarks about "rich".

It is this - that 'rich' is subject to accommodation and negation (A\&N, for short)-that explains why 'Mary is rich' expresses a claim whose truth is relative. (Richard, 2008, p. 100).

There are different ways of developing the idea of relative truth. ${ }^{10}$ However, for present purposes, the idea is that the content of an utterance is true or false relative to something. For example, one common view has it that utterances express propositions which have truth-values relative to possible worlds; the proposition that grass is green is true when evaluated at the actual world, but that very same content is false when evaluated at a possible world where grass is red.

In Kaplan's (1989) framework, contents are evaluated relative to a circumstance of evaluation, which Kaplan conceives of as including both a world and a time. However, one could add additional parameters, such as a parameter for standards of precision. " In that case, the content of Mary's utterance of "France is hexagonal" could be true relative to some standards of precision, but false relative to others.

[Thesis 3] is a claim about the truth-value of an utterance. On the kind of view we are considering, in order to determine the truth-value of an utterance, we will need to evaluate the content of that utterance relative to a circumstance of evaluation. We can reject [Thesis 3] if we maintain that the circumstance of evaluation at which we ought to evaluate the content of an utterance can be determined by things that take place after that utterance. For instance, in [Case A], John's willingness to accommodate means that we ought to evaluate Mary's utterance at a circumstance that includes low standards of precision. In this case, Mary's utterance is true. In [Case B], on the other hand, Mary goes along with the higher standards of precision, and this means that we ought to evaluate Mary's utterance at a circumstance that includes high standards of precision. In this case, Mary's utterance is false. This allows the truth-value of the utterance to vary even if the content stays the same. It also allows something that happens after an utterance to make a difference to its truth-value, by making a difference to the circumstance of evaluation.

Relativist views of this kind differ along a number of dimensions. For the purpose of the present discussion, the main question is how the relevant standards are determined. If Mary's original utterance of "France is hexagonal" is true in [Case A], but false in [Case B], there are different ways of making sense of that within a relativist framework. Furthermore, as we observed in Sect. 4, there are

\footnotetext{
${ }^{10}$ See e.g. Richard (2008) and MacFarlane (2014) for influential recent discussions.

11 See e.g. also Lewis (1980). In Lewis' framework, the index contains a standard of precision parameter in order to account for expressions like "strictly speaking". The index plays a role in some respects similar to Kaplan's (1989) circumstance of evaluation. However, Lewis does not commit to the idea that the contents of utterances are true and false only relative to a standard of precision parameter. His view is that the compositional semantic values of sentences are true and false relative to standards of precision, but he maintains that the contents of utterances may not be identical to compositional semantic values.
} 
cases, such as [Case C], in which Mary and John appear to be having a disagreement. How this can be explained depends on how the relevant standards are determined. For instance, are Mary and John employing different standards or is there a fixed set of standards in play throughout the conversation? In what follows, we will outline two options. There are undoubtedly other options, but given the puzzle under discussion, only options that reject [Thesis 3] are relevant.

The first option allows that there is a sense in which Mary and John are employing different standards of precision, at least before they come to an agreement. However, even if the standards differ, there is still the content that France is hexagonal. Insofar as Mary accepts that content and John rejects it, could that be sufficient for them to disagree? That is controversial. ${ }^{12}$ For instance, as MacFarlane (2007) observes, accepting and rejecting the same content is not sufficient for disagreement if it is a tensed content that has different truth-values relative to different times. According to MacFarlane, if we wanted to say that Mary and John disagree, we would have to say that the standard of precision parameter is determined by the context of assessment. That would make it different from the time parameter, which is determined by the context of use.

This way of explaining disagreement in relativist terms has already been thoroughly explored in the literature and we do not have much to add to the existing discussion here. If one is already comfortable with these kinds of resources, then it seems to offer a way out of the puzzle. If one is not, then one has to look elsewhere. It is also worth noting that this still amounts to rejecting [Thesis 3]. If Mary and John ultimately adopt the same standards, as they do in [Case A] and [Case B], they will presumably evaluate the previous utterances in the conversation relative to those standards. Using MacFarlane's terminology, we could then say that accommodation makes a difference to the truth-value of an utterance by making a difference to the context of assessment that is responsible for determining the relevant standards of precision. ${ }^{13}$ It is because this can happen after the utterance that [Thesis 3] fails according to this proposal.

However, there is also a second option that arguably avoids some of the commitments of the previous option. Unlike the previous option, it treats the content of Mary and John's utterances as evaluated with respect to the same circumstance of evaluation throughout the conversation. This raises the question of what the relevant standards of precision are. There are obviously different answers, but we are going to focus on the option that we take to be most relevant for the purpose of the present discussion. That is to say that the relevant standards are the standards that are in play at the end of the conversation, after the process of accommodation has run its course. For instance, in [Case A], it would be the lower standards that prevail, whereas in [Case B] it would be the higher standards that prevail. This makes the

\footnotetext{
12 See e.g. Glanzberg (2007), Stojanovic (2007), Rosenkranz (2008), Cappelen and Hawthorne (2009), and Francén (2010) for critical discussion.

13 Strictly speaking, MacFarlane does not ascribe truth or falsity to utterances. Instead, he talks about utterances being accurate or inaccurate. See e.g. MacFarlane (2014, ch. 3) for relevant discussion. However, the present discussion could easily be restated using MacFarlane's preferred terminology.
} 
disagreement much easier to handle. Mary's acceptance and John's rejection can simply be evaluated with respect to the same circumstance of evaluation.

This option still makes use of the basic relativist machinery inasmuch as the relevant contents are true or false relative to a standard of precision. Having said that, there is no need for a special account of disagreement. For instance, there is no need for something like the context of assessment to play a role in the account. It is enough to say that the process of accommodation that takes place after the utterance can make a difference to the relevant circumstance of evaluation.

\subsection{Making a difference to content}

We have so far been discussing ways that something can make a difference to the truth-value of an utterance without making a difference to the content of the utterance. But, as we noted above, there is a second strategy for rejecting [Thesis 3]: one could maintain that [Thesis 3] is false because things that take place after an utterance occurs can sometimes make a difference to the content of that utterance.

In the previous sub-section, we considered relativist views, according to which propositions are true and false relative to parameters such as a standard of precision. Let us assume for now that propositions are true and false at a world, and that no further relativisation is needed. In that case, an utterance of "France is hexagonal" will express a proposition that is true or false at a world depending on France's shape at that world. Exactly which proposition is expressed will vary. Some utterances of "France is hexagonal" may express the proposition that is true at a world just in case France is precisely hexagonal at that world, while others may express the proposition that is true at a world just in case France's shape is reasonably close to hexagonal.

What makes it the case that a particular utterance of "France is hexagonal" expresses one of these propositions rather than the other? A familiar style of view would have it that the speaker's intentions at the time of utterance determine what proposition is expressed. But this view fails for reasons we have already described in Sect. 4. It cannot make sense of John's reaction and Mary's response in [Case B]. An alternative would have it that some other facts about the environment at the time of utterance determine what proposition is expressed. But, as we have already argued, it is doubtful that there are any such facts that can do the job in a way that does justice to the phenomena.

A more plausible view could be modelled on the view of the circumstances of evaluation developed in the previous sub-section. We suggested there that the standards of precision might be determined in part by the view that the parties to the conversation arrive at. And we suggest that a similar view is attractive in the present framework as a view about what determines content. In [Case B], the fact that John and Mary come to agree that Mary's utterance of "France is hexagonal" is false would tend to make it the case that that utterance expresses a false proposition-a proposition that is true at a world just in case France is precisely hexagonal at that world. In [Case C], the fact that John and Mary come to agree that Mary's utterance of "France is hexagonal" is true would tend to make it the case that that utterance 
expresses a true proposition - a proposition that is true at a world just in case France's shape is roughly hexagonal. ${ }^{14}$

The view is a version of externalism about content, since on it, the facts about the content of an utterance fail to supervene on facts internal to the speaker at the time of utterance. A minimal supervenience base for the facts about the content of an utterance would have to include things that take place after that utterance. This view is sometimes called temporal externalism in the literature. ${ }^{15}$ As a variety of externalism, it is subject to a number of standard objections. For example, a number of philosophers have worried that externalism makes introspective self-knowledge impossible. If what we mean is determined by external facts, and we cannot know those external facts by introspection, then how can we know what we mean by introspection?

A full discussion of this objection would require a paper of its own. Here we will only aim to show that the temporal externalist view we have described is no worse off than standard forms of externalism, such as those inspired by, say, Kripke (1980) or Putnam (1975). Furthermore, the view can in fact avail itself of a standard externalist reply. A standard externalist reply to worries about self-knowledge points out that when one forms a higher-order representation - a thought about what one thinks or means - the conceptual resources one uses to characterise what one thinks or means are precisely the same conceptual resources one would use in the first order representation that one is thinking about. ${ }^{16}$ For instance, if in thinking or asserting that water is wet one employs the concept of water, one would employ exactly that same concept in thinking that one thinks or asserts that water is wet. Since the concepts are the same, their contents are fixed by the same internal and external factors. For instance, if the presence of $\mathrm{H}_{2} \mathrm{O}$ in my environment plays a role in determining the content of my thought or assertion that water is wet, it will play just the same role in determining the content of my thought that I think or assert that water is wet. There is, therefore, no possibility that my higher-order thought will be false in virtue of external, content-determining facts. This suggests that externalism poses no threat to self-knowledge.

Of course, there is much more to be said. But it is worth noting that this style of reply is open to externalists no matter what external facts they maintain play a content-determining role. In particular, even if things that take place after an utterance can play a role in determining the content of that utterance, those things will play the same role in determining the content of higher-order representations of the content of that utterance. Thus it is plausible that those who wish to resolve the puzzle by maintaining that [Thesis 3] is false because things that take place after an utterance occurs can sometimes make a difference to the content of that utterance, can make sense of self-knowledge as well as, and in the same way as, other externalists.

\footnotetext{
14 An advantage of this kind of view is that it provides a simple account of the disagreement in [Case C]. There is a proposition that one party accepts and the other rejects, and this proposition is only true or false relative to worlds.

15 See e.g. Jackman (1999, 2005) and Ball (2020a, 2020b) for discussion.

16 There are many versions of this style of reply in the literature. One locus classicus is Burge (1988).
} 
Having said that, there are also objections that are specific to temporal externalism, and do not apply to other externalist views. Another line of objection to temporal externalism is that the view would make the content of many utterances indeterminate. For instance, it might be observed that in many cases, conversations end without all parties reaching agreement. ${ }^{17}$ Perhaps John gets called away before he can respond to Mary's claim, or perhaps John and Mary debate about whether France is hexagonal for an hour and eventually have to let the matter drop. In this kind of case, it does not seem as though John and Mary have done enough to determine the conversational score. It does not seem as though accommodation has taken place, but it also does not seem as though John and Mary have done anything that would rule out accommodation.

In response to this objection, we suggest that in this kind of situation, it is plausible to maintain that the content of Mary's utterance is indeterminate. After all, suppose that Mary and John were to resume their discussion. Then they might come to agree that Mary was right and conclude that France is hexagonal. In that case, it would be natural to count Mary's utterance of "France is hexagonal" as expressing a true content. But they might also come to agree that Mary was wrong and conclude that France is not hexagonal. In that case, it would be natural to count Mary's utterance of "France is hexagonal" as expressing a false content. Since both options would be open to them, the content of Mary's utterance is indeterminate.

We therefore conclude that the objections to this way of rejecting [Thesis 3] are not decisive. The solution to the puzzle that maintains that things that take place after an utterance occurs can make a difference to the content of that utterance is an open possibility.

\subsection{Two contexts}

Finally, there is a position that deserves special mention. While he is not responding to the puzzle that we have presented, Richard (1995, pp. 565-566) allows that accommodation can make a difference to the truth-value of an utterance even if the utterance is not about the future. ${ }^{18}$ However, there is an important caveat. Richard argues that an utterance, such as Mary's utterance of "France is hexagonal", can have two truth-values. In order to make sense of this, he distinguishes between the local context and the global context. ${ }^{19}$ The local context is determined by the facts at the time of the utterance. The global context is determined by the conversation as

\footnotetext{
17 A second way of developing the objection would be to claim that the future is open, in the sense that at least some claims about the future are neither true nor false. This is a highly controversial claim about the metaphysics of time that many philosophers may be antecedently disposed to reject. But for those disposed to accept it, we would suggest that commitment to indeterminacy of meaning in the kind of case we are discussing is just as plausible as other commitments of the view. For example, the proponent of the open future is committed to the claim that the content of Mary's utterance is indeterminate at the time she makes it, and also to the claim that it is indeterminate whether the sun will rise tomorrow. It is hardly clear that the former claim is problematic in a context where we have taken on board the latter.

18 Richard's (1995) main concern is attitude reports, but that does not matter here.

19 In talking about the local context and the global context, we are following Richard's (1995, p. 566) terminology.
} 
a whole. For instance, in [Case B], Mary's initial utterance could be true relative to the local context, but false relative to the global context.

There are different ways of developing Richard's proposal. For instance, the utterance could be said to have two truth-values in virtue of having two contents. There is the content that is determined by the local context and the content that is determined by the global context. This means that accommodation makes a difference to the content of the utterance, along the lines of the temporal externalist option outlined in sub-Sect. 5.2 above. ${ }^{20}$ Alternatively, the utterance could be said to have two truth-values in virtue of being evaluated with respect to two circumstances of evaluations. There is the circumstance of evaluation that is determined by the local context and the circumstance of evaluation that is determined by the global context. This is in line with the relativist option outlined in sub-Sect. 5.1 above, as well as Richard's more recent contributions (Richard, 2008).

In either case, it is the local context that is Richard's main addition to the previous proposals. It allows us to have two contents or two circumstances of evaluation, as opposed to just the one that is determined by the global context. In principle, there is nothing wrong with this addition. The question is what it does for us, especially in terms of solving the puzzle under discussion.

There are a couple of points to make here. The first point concerns Richard's (1995, pp. 565-566) motivations for distinguishing the local and the global context. Richard argues that an utterance can have two truth-values. An earlier utterance can be true when it is made even if it is false by the end of the conversation. For instance, in [Case B], Mary's initial utterance could be true relative to the local context, but false relative to the global context. However, it is unclear whether that is something we have to accept. There does not appear to be anything in the process of accommodation that requires that Mary's utterance must have a truth-value that is independent of the subsequent course of the conversation. In particular, there does not seem to be anything incoherent about saying that there is only the truth-value that is determined by the global context, to use Richard's terminology.

Perhaps one could argue that even in [Case B], it just seems that Mary's initial utterance was true before it was challenged by John. However, there are reasons for doubting that there are any clear judgments about that. In Sect. 4, we pointed out that it was unclear what could make it correct for John to respond one way or another. The same considerations seem to make it difficult to say whether Mary's utterance was true or false before it was challenged.

The second point concerns the challenges that were raised for the relativist and temporal externalist proposals in Sects. 5.1 and 5.2, respectively. These challenges seem to remain even with the addition of the local context. For instance, if one is still worried that the temporal externalist option would undermine our selfknowledge, that worry would still arise for the content that is determined by the global context. Even if the issue does not arise with respect to the content that is

\footnotetext{
${ }^{20}$ This way of developing the proposal arguably makes sense given what Richard (1995, p. 566) says about what happens in the conversation "effecting what was said by earlier uses of sentences in which the predicate occurs". However, for present purposes, we are more interested in the space of possible views than in such exegetical questions.
} 
determined by the local context, there seems to be little comfort in that. Similarly, if one has concerns about the relativist machinery or how it handles disagreement, the addition of the local context does not seem to help much with that either.

In summary, the issue is not whether there is anything inherently wrong with distinguishing the local and the global context in the way that Richard does. It seems that this idea could be developed either along relativist or temporal externalist lines. However, as far as the present discussion is concerned, it does not seem to change the evaluation of either option in any significant way.

\section{Conclusion}

We have presented a puzzle about accommodation, based on the inconsistency of three plausible claims:

1. Accommodation takes place after an utterance.

2. Accommodation can make a difference to the truth-value of an utterance even if the utterance is not about the future.

3. Something that takes place after an utterance cannot make a difference to the truth-value of the utterance unless the utterance is about the future.

Denying any of these theses comes with theoretical costs. But we have suggested that the best solution to the puzzle is to reject the third claim and have proposed two kinds of strategies for doing so. The first strategy maintains that accommodation makes a difference to the circumstance at which a relatively true content is evaluated. The second strategy maintains that accommodation makes a difference to the content itself. That said, both strategies are controversial and which strategy one prefers will depend on one's opinions of relativist and externalist views.

This is an important and fundamental dispute about the architecture of semantic theory and the metaphysics of meaning. But settling it is a project for another paper.

Acknowledgements Earlier versions of this paper were presented at the New Frontiers of Speech Workshop at Uppsala University in February 2019, the Higher Seminar in Philosophy at Umeå University in May 2019, the Arché Language and Mind Seminar at the University of St Andrews in May 2020. We are grateful to the audiences on those occasions for helpful discussion. We are particularly grateful to Ravi Thakral for helpful comments. Research for this paper was supported by Torfinn Huvenes' Vetenskapsrådet Research Project Grant (2017-03222) Disagreement in Language and Thought.

Funding Open access funding provided by Umea University.

Open Access This article is licensed under a Creative Commons Attribution 4.0 International License, which permits use, sharing, adaptation, distribution and reproduction in any medium or format, as long as you give appropriate credit to the original author(s) and the source, provide a link to the Creative Commons licence, and indicate if changes were made. The images or other third party material in this article are included in the article's Creative Commons licence, unless indicated otherwise in a credit line to the material. If material is not included in the article's Creative Commons licence and your intended use is not permitted by statutory regulation or exceeds the permitted use, you will need to obtain permission directly from the copyright holder. To view a copy of this licence, visit http:// creativecommons.org/licenses/by/4.0/. 


\section{References}

Ball, D. (2018). Lewisian scorekeeping and the future. Croatian Journal of Philosophy, 18, 375-384.

Ball, D. (2020a). Revisionary analysis without meaning change; or, could women be analytically oppressed? In A. Burgess, H. Cappelen, \& D. Plunkett (Eds.), Conceptual ethics and conceptual engineering (pp. 35-58). Oxford University Press.

Ball, D. (2020b). Relativism, metasemantics, and the future. Inquiry, 63, 1036-1086.

Brown, J. (2000). Against temporal externalism. Analysis, 60, 178-188.

Burge, T. (1988). Individualism and self-knowledge. The Journal of Philosophy, 85, 649-663.

Cappelen, H., \& Hawthorne, J. (2009). Relativism and monadic truth. Oxford University Press.

Francén, R. (2010). No deep disagreement for new relativists. Philosophical Studies, 151, 19-37.

Gauker, C. (2008). Against accommodation. Philosophical Perspectives, 22, 171-205.

Glanzberg, M. (2007). Context, content, and relativism. Philosophical Studies, 136, 1-29.

Heim, I. (1992). Presupposition projection and the semantics of attitude verbs. Journal of Semantics, 9 , 183-221.

Jackman, H. (1999). We live forwards but understand backwards: Linguistic practices and future behavior. Pacific Philosophical Quarterly, 80, 157-177.

Jackman, H. (2005). Temporal externalism, deference, and our ordinary linguistic practice. Pacific Philosophical Quarterly, 86, 365-380.

Kaplan, D. (1989). Demonstratives. In J. Almog, J. Perry, \& H. Wettstein (Eds.), Themes from Kaplan (pp. 481-563). Oxford University Press.

Kennedy, C. (1997). Projecting the adjective: The syntax and semantics of gradability and comparison. Ph.D. Thesis, University of California, Santa Cruz.

Kennedy, C., \& McNally, L. (2005). Scale structure, degree modification, and the semantics of gradable predicates. Language, 81, 345-381.

Kripke, S. (1980). Naming and Necessity. Harvard University Press.

Lewis, D. (1979). Scorekeeping in a language game. Journal of Philosophical Logic, 8, 339-359.

Lewis, D. (1980). Index, context, and content. In S. Kanger \& S. Öhman (Eds.), Philosophy and grammar (pp. 79-100). Reidel.

Ludlow, P. (2014). Living words. Oxford University Press.

MacFarlane, J. (2007). Relativism and disagreement. Philosophical Studies, 132, 17-31.

MacFarlane, J. (2014). Assessment sensitivity: Relative truth and its applications. Oxford University Press.

Plunkett, D., \& Sundell, T. (2013). Disagreement and the semantics of normative and evaluative terms. Philosophers' Imprint, 13, 23.

Putnam, H. (1975). The meaning of "meaning." Minnesota Studies in the Philosophy of Science, 7, 131-193.

Richard, M. (1995). Defective contexts, accommodation, and normalization. Canadian Journal of Philosophy, 25, 551-570.

Richard, M. (2008). When truth gives out. Oxford University Press.

Roberts, C. (1989). Modal subordination and pronominal anaphora in discourse. Linguistics and Philosophy, 12, 683-721.

Rosenkranz, S. (2008). Frege, relativism and faultless disagreement. In M. García-Carpintero \& M. Kölbel (Eds.), Relative truth (pp. 225-237). Oxford University Press.

Stalnaker, R. (1998). On the representation of context. Proceeding of SALT, 6, 279-294.

Stanley, J. (2005). Knowledge and practical interests. Oxford University Press.

Stojanovic, I. (2007). Talking about taste: Disagreement, implicit arguments, and relative truth. Linguistics and Philosophy, 30, 691-706.

von Fintel, K. (2008). What is presupposition accommodation, again? Philosophical Perspectives, 22, 137-170.

Publisher's Note Springer Nature remains neutral with regard to jurisdictional claims in published maps and institutional affiliations. 